\title{
Application of mathematical modelling for draw control under material flow uncertainty
}

\author{
F Khodayari University of Alberta, Canada \\ Y Pourrahimian University of Alberta, Canada \\ E Ben-Awuah Laurentian University, Canada
}

\begin{abstract}
Production scheduling is one of the key steps in the decision-making process of any mining operation. In block caving, it is the choice of the amount of caved rock to extract from drawpoints in different periods. One of the main differences between block caving and other mining methods is the influence of the material flow on production, and draw control in general. Achieving an optimum production schedule without consideration of the cave rate and material flow could be unrealistic and impractical as the movements of material between drawpoints will result in unexpected production grades and tonnages.

In this paper, a stochastic mixed integer optimisation model is proposed to optimise the production schedule during the life of the mine. The uncertainties of production grades and tonnages are captured by defining a number of scenarios that represent the probable movements of fragmented rock between drawpoints in the same neighbourhood. The decision variables in the formulation are based on the slice model, which means that the mathematical solution determines which slices are extracted from drawpoints in each period of production. The goal is to maximise the net present value of the project during the life of the mine and minimise the deviations of production grades and tonnages from the defined goals in all probable scenarios resulting from the movements of the fragmented rock between drawpoints. Application of the proposed model in caving operations can not only improve the profitability of the project, but also increase the confidence of the production schedule.

MATLAB was used for programming and CPLEX for solving the model. The designed graphical user interface, with the capability of adding different technical and operational constraints, will be a flexible tool for mine planners to control the draw based on the company's goals during the life of the mine.
\end{abstract}

Keywords: block caving, production scheduling, draw control, material flow, stochastic optimisation

\section{Introduction}

As the number of block cave mines in the world is increasing, the challenges of this mining method are the subject of increased investigation and investment. Draw control plays a critical role both for operational and financial purposes. Good draw control can improve safety outcomes and fragmentation, which results in fewer hang-ups, all of which increases the efficiency of the processing plant. This will lead to improved financial outcomes for the owners. Mathematical modelling can be used to optimise the production from drawpoints while considering operational constraints. As a result, many researchers have used mathematical models to optimise the production of block cave mining. Rubio (2002) maximised the net present value (NPV) of the project and the life of the mine. A similar goal was achieved by Diering (2004) using a linear programming model. He later applied quadratic programming to control the shape of the cave. Rahal et al. (2008) minimised the deviations from production targets using a mixed integer linear programming model. In other research, the production schedule of Northparkes E48 mine was optimised by Rahal et al. (2008). Optimisation of the production schedule at three different levels of resolution (cluster level, drawpoint level, and drawpoint-and-slice level) was first 
introduced by Pourrahimian et al. (2013). This model made it possible to spend a reasonable amount of time investigating the financial viability of block cave operations based on the level of required precision. Khodayari and Pourrahimian (2014) included the calculation of best height of draw (BHOD) in the production scheduling optimisation model to be an output of the mine plan and not an input. A more detailed review of the mathematical models and their applications in block cave mining production scheduling was presented by Khodayari and Pourrahimian (2015b).

Almost none of the mentioned mathematical models have considered material flow uncertainties as part of the optimisation models. A production scheduling model was proposed by Khodayari and Pourrahimian (2017) to maximise the NPV of the project and minimise the production grade deviations. They considered only horizontal movements of the fragmented rock during the caving operations. It was shown that stochastic optimisation can be a strong tool for the purpose of material movement modelling. The uncertainties of material flow can change the outputs of the production in a block cave mining operation. Unlike open pit mining, the production grades and tonnages can vary from the expected values of the mine plan. In such a situation, any strategic decision should be made with the consideration of movements of the fragmented rock within the cave. Since the processing plant relies on the mine production, the production tonnages and grades should be realistically considered for the draw control purposes during the life of the mine. Stochastic optimisation can play a critical role to model the material movements and its uncertainties during production. In this paper, a draw control strategy for block cave mining is proposed in which the material flow and its uncertainties are modelled within the mine plan. In the following section, the concept of the proposed methodology is presented. Because of the importance of the concept, this paper focuses on explaining the underlying logic and theory behind the model rather than the details of the explicit mathematical formulation.

\section{Methodology}

In order to capture the uncertainties of material flow during production, it is important to consider the possible movements of the fragmented rock as it moves down into the drawpoints. This could be done by defining a number of scenarios and considering them in the production scheduling optimisation model. Based on the full-scale marker experiments that Alvial (1992, as cited in Laubscher (2000)) carried out at El Teniente block caving mine, the horizontal displacement of the markers can be up to $42 \mathrm{~m}$ within a slip angle of $60^{\circ}$. In this paper, these parameters are used to define the cone of movement (CoM). This is the cone in which the fragmented rock can possibly move within its neighbourhood (Figure 1).

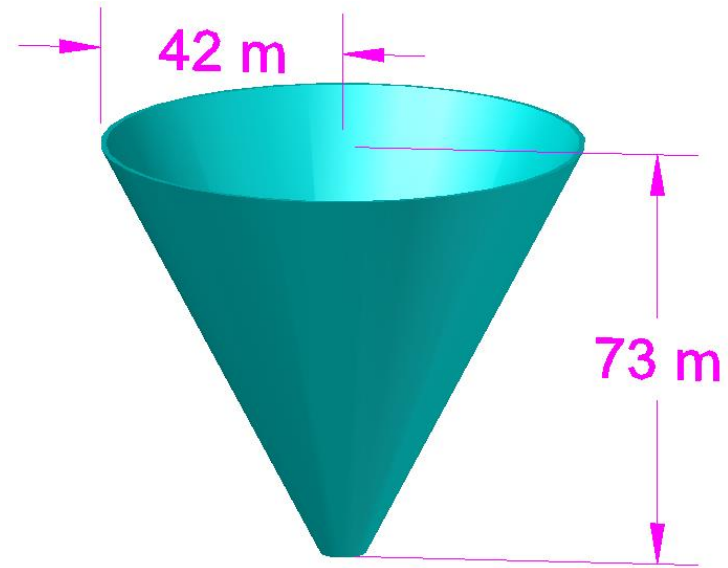

Figure 1 The CoM dimensions based on the experimental results

For each drawpoint in each slice horizon (elevation of the bottom of the slice), a CoM is defined to be used for the model. While extracting the material, the fragmented rock can move from the draw column above or the other ones in the neighbourhood into the drawpoint (Figure 2). The slices that fall inside the CoM are considered to define the scenarios for that specific drawpoint in that horizon. 


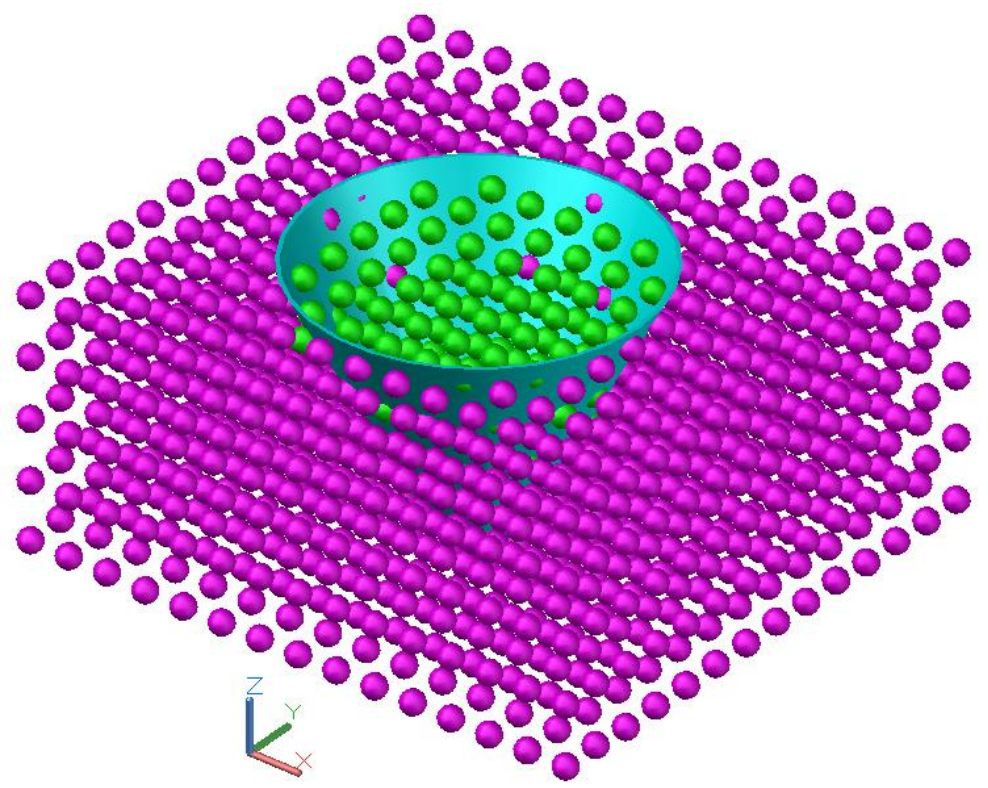

Figure 2 Defining the boundary in which the slices in the neighbourhood can fall into a specific drawpoint at the time of extraction. Each ball represents one slice

Figure 3 presents the cones in the same neighbourhood and how they can overlap based on the distance of the drawpoints. The shape of the CoM and number of scenarios depend on the nature of the orebody, geometry of the drawpoints and how they are located in the layout compared to each other, and the rock properties. Each scenario represents one possible set of movements that can occur during extraction. Using this concept, both vertical and horizontal movements are considered in the optimisation model. The goal is to maximise the NPV of the project with consideration of material movements (horizontal and vertical) and to achieve the production targets with respect to the defined mining and geotechnical constraints while meeting the processing plant's metallurgical requirements. A simplified description of the model is as follows:

for all defined scenarios $\rightarrow\left\{\begin{array}{c}\text { Maximise NPV } \\ \& \\ \text { Minimise Ore and Grade Deviations }\end{array}\right\}$

$\rightarrow$ while considering material movements, production targets are achieved

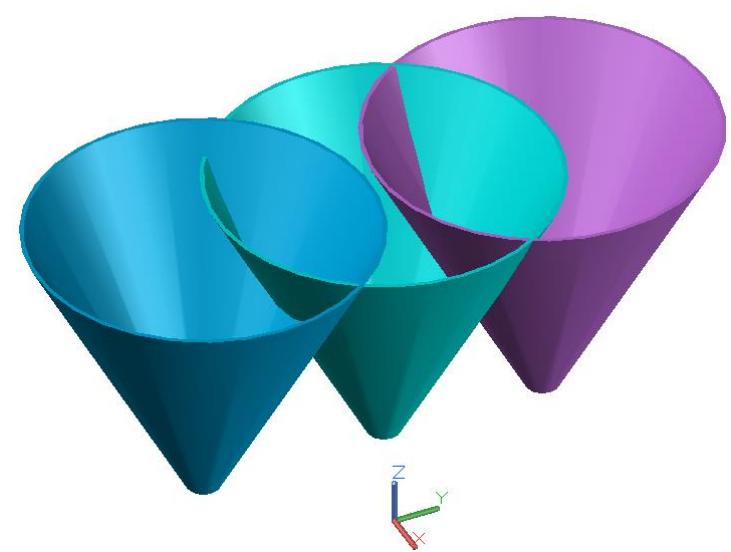

Figure 3 Different CoMs in the same neighbourhood and their overlap 


\section{Application and results}

The optimisation model with the proposed mixing methodology was tested for a copper block cave mining operation that is based on 410 drawpoints (Figure 4). The mathematical formulation, including the objective function and constraints, is a modified version of the model that was presented by Khodayari and Pourrahimian (2017). The updated version considers both horizontal and vertical mixing rather than only horizontal mixing, which the previous model was based on. Additionally, it minimises the deviations of production tonnage and grade while only grade deviations were minimised in the last version. The number of slices in the drawpoints ranges from 16 to 60 with a height of $15 \mathrm{~m}$. Figures 5 and 6 show the grade and tonnage distributions among the slices.

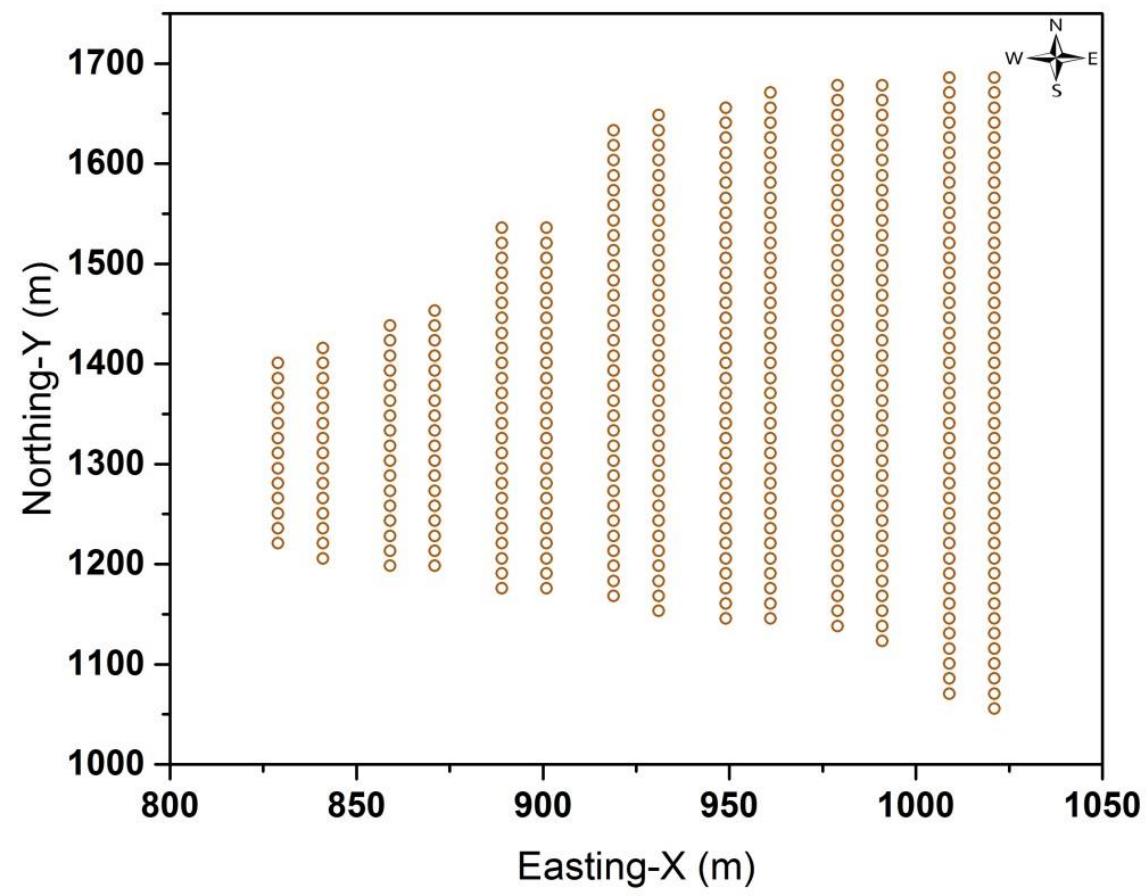

Figure 4 Layout of drawpoints

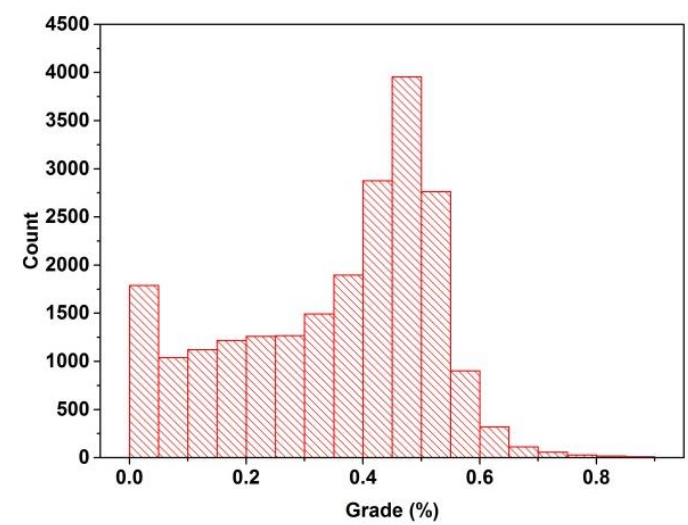

Figure 5 Grade distribution among the slices

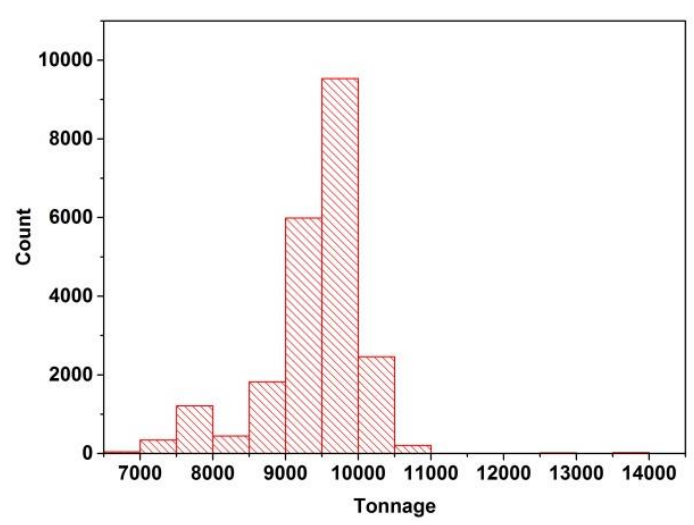

Figure 6 Tonnage distribution among the slices

The best mining direction in the block cave layout is defined based on the methodology that was proposed by Khodayari and Pourrahimian (2015a). Figure 7 shows the optimum mining direction for achieving maximum profit during the life of the mine. This direction is used as a guideline to develop the sequence of extraction among the drawpoints within the layout. 


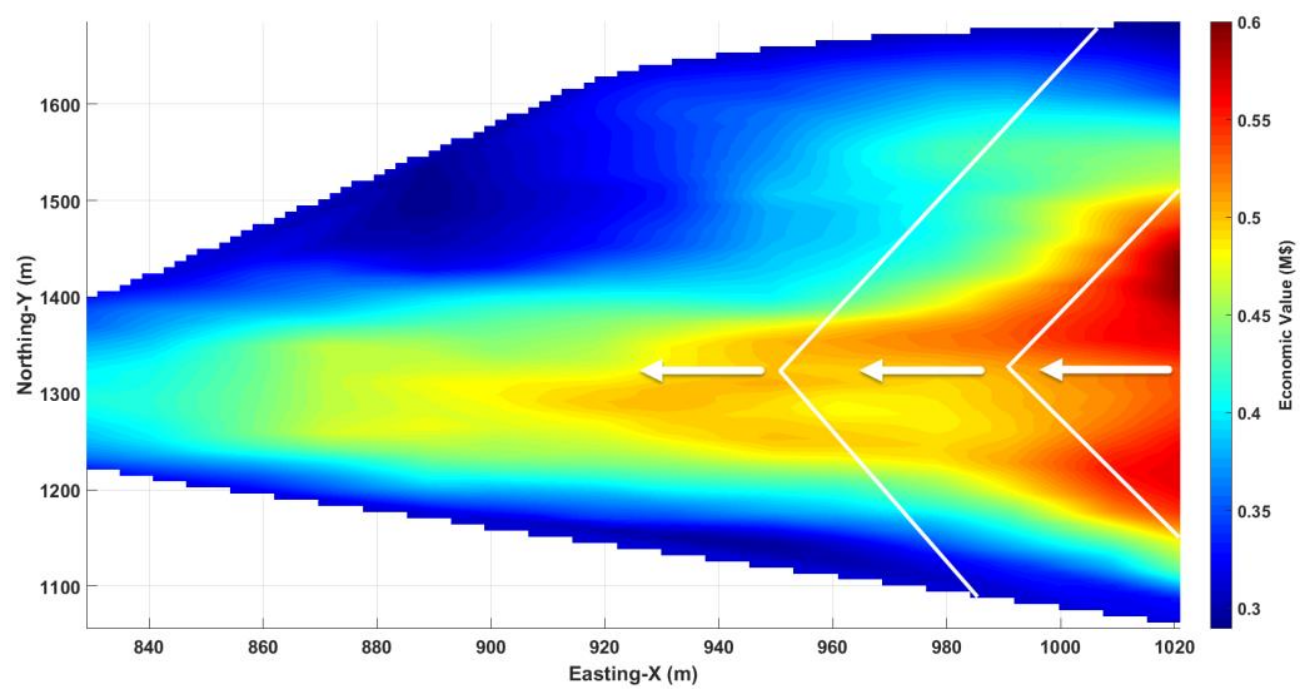

Figure 7 The best potential mining direction in the block cave layout

The goal is to achieve both production tonnages and grades while considering material flow uncertainties. Production tonnages, production grades, the number of active drawpoints in each period, and their sequence of extraction are the main constraints to be considered for this example. Running the model for this case study indicated that $127 \mathrm{Mt}$ of ore is produced with an NPV of USD 279.8 million over 20 years of operation. In addition, the production tonnages and grades are at the target values. The production starts with $3 \mathrm{Mt}$ in the first year and increases to $7 \mathrm{Mt}$ within a three-year ramp-up period (Figure 8).

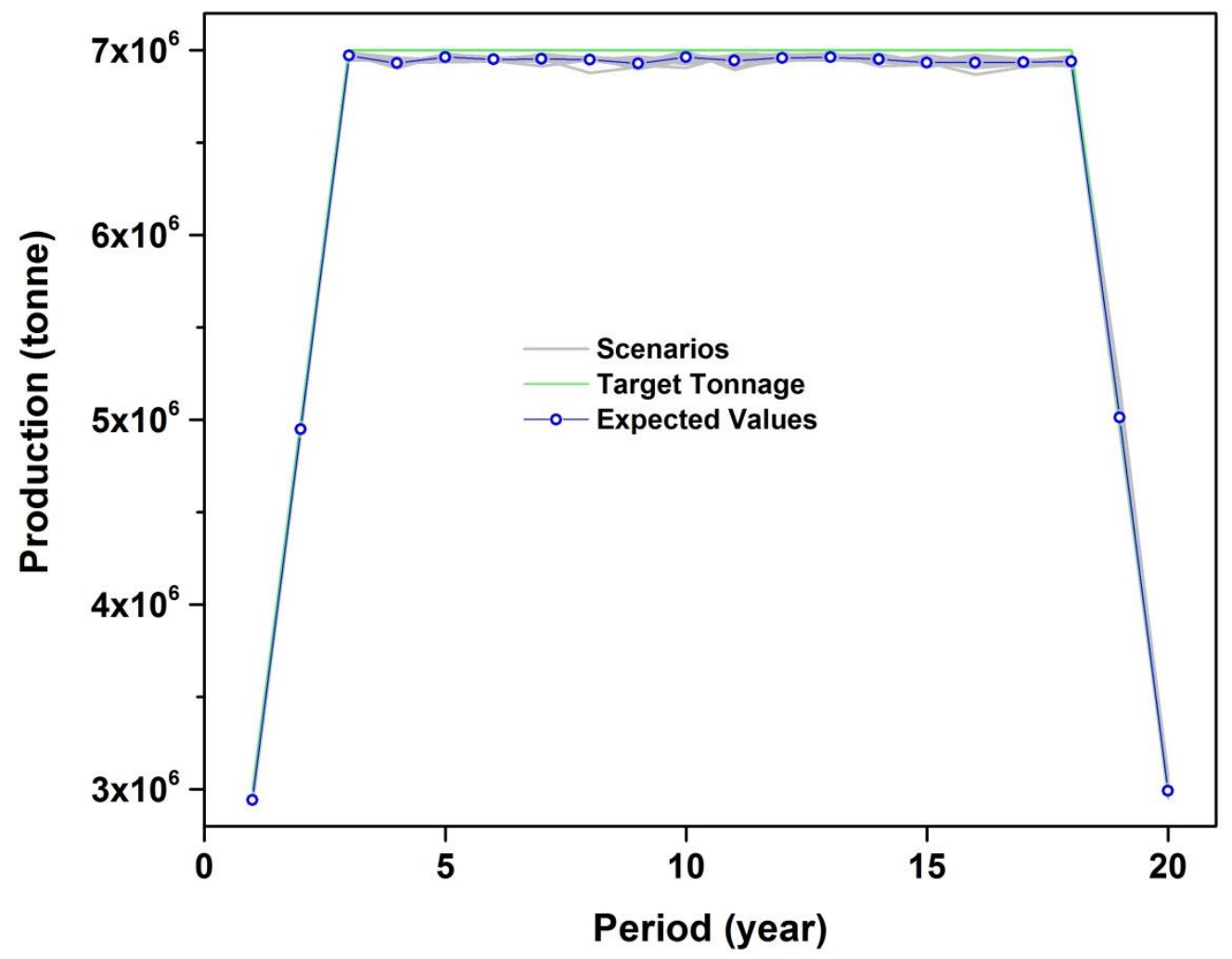

Figure 8 Ore production during the life of the mine

Figure 9 shows the production grade profile which deviates from the target grade of $0.45 \%$ of $\mathrm{Cu}$. In addition, the expected sequence of extraction based on the $V$-shape mining direction is achieved (Figure 10). The sequence of extraction and NPV maximisation explain the higher and lower production grades at the first and last few years of the mine life. 


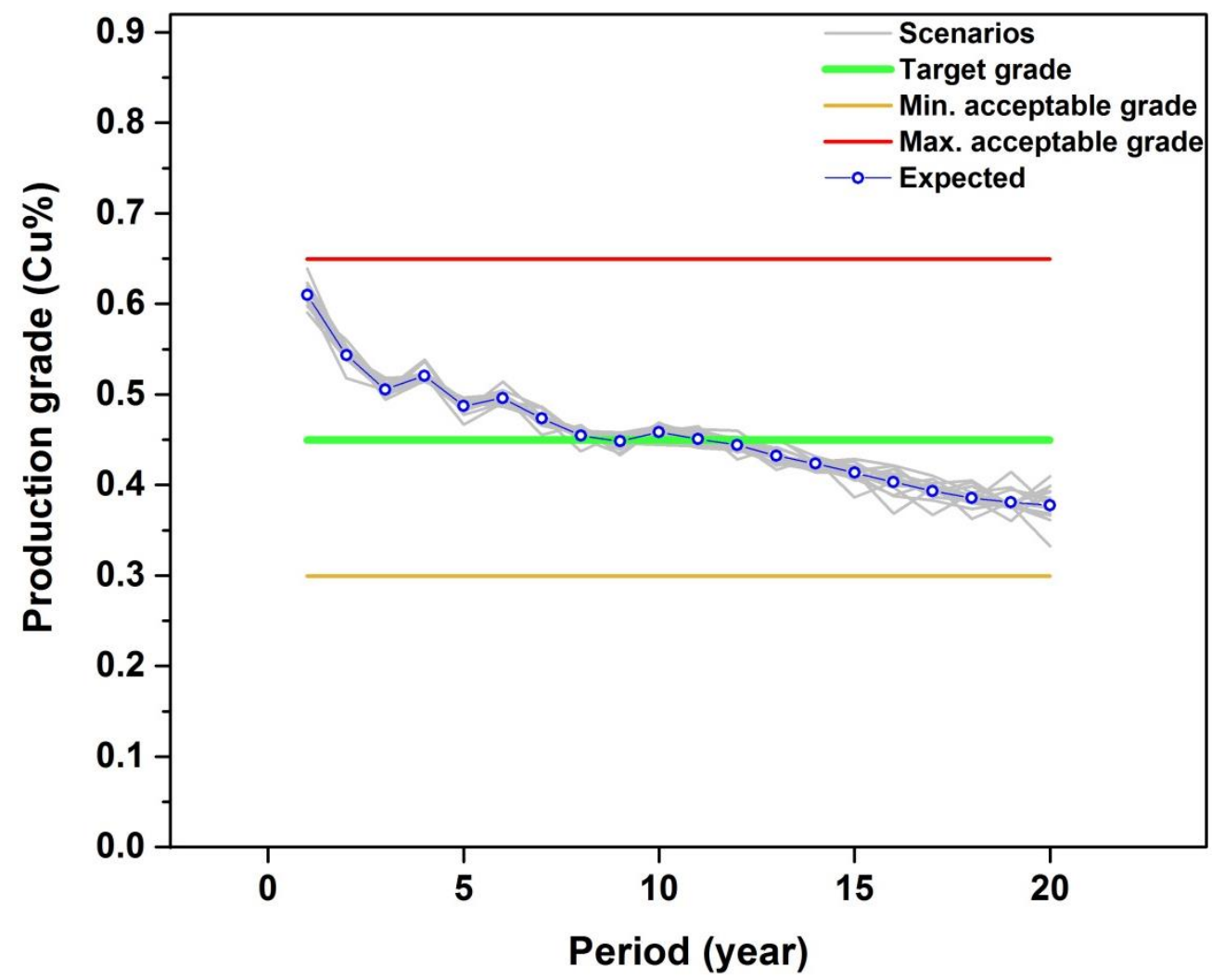

Figure 9 Production grade during the life of the mine
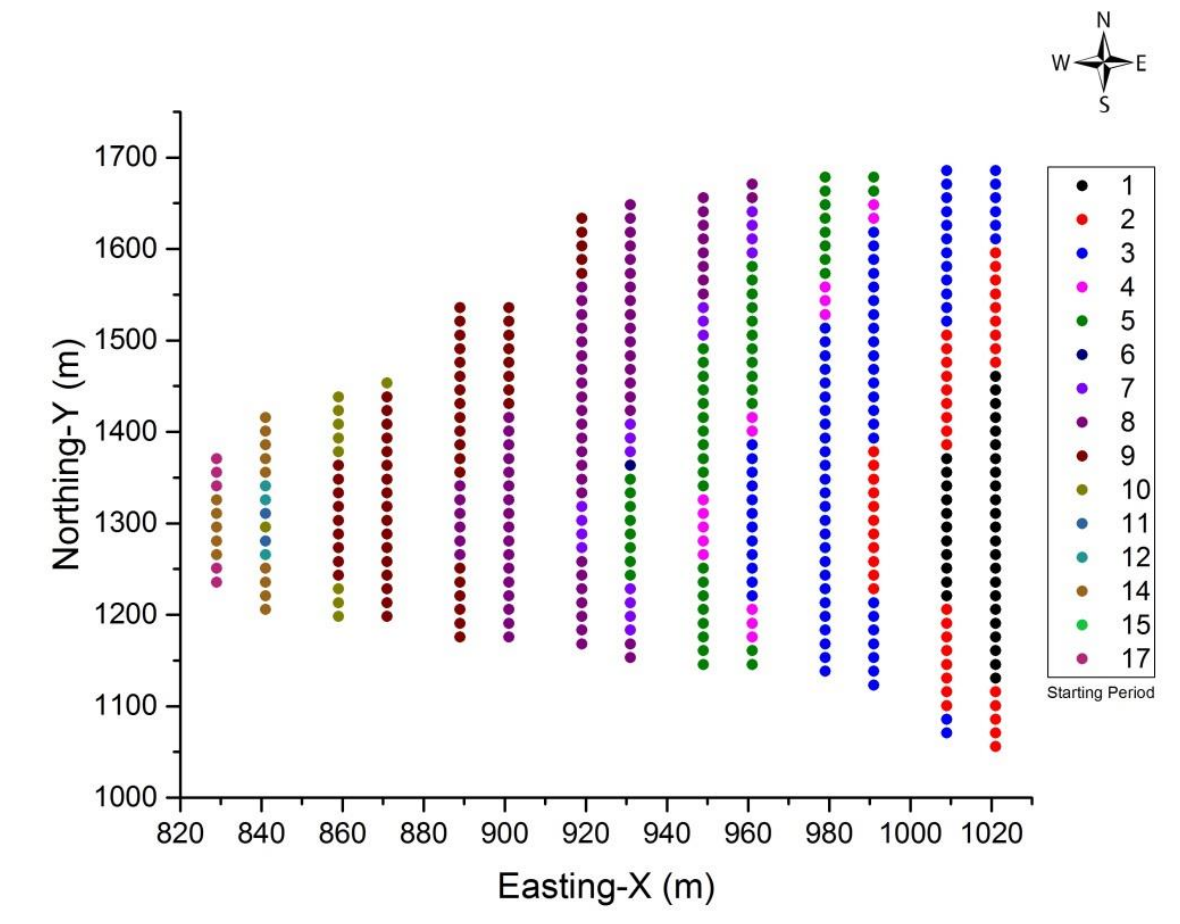

Figure 10 Sequence of extraction for drawpoints 


\section{Conclusion}

In this paper, a methodology was proposed to optimise the production schedule in block cave mining operations in the presence of material flow uncertainties. Defining the CoM helps understand the material movements within the cave area during production. As a modelling tool, it facilitates the process of generating various possible mixing scenarios. Using this concept in the optimisation model can lead us to improved production schedules, and as a result, higher efficiencies. Testing the model for a block cave mining project showed that the NPV of the project during the life-of-mine is maximised and the production and grade targets are achieved with respect to the defined constraints. Each scenario represented a series of movements and the model proposed a schedule in which the deviations from the target production tonnages and grades are minimised for all scenarios. Production targets are closely related to the mineral resource, operational limitations, and economic considerations. Based on the preferences of the management team, the model can be adapted to achieve satisfactory results.

\section{References}

Diering, T 2004, 'Computational considerations for production scheduling of block cave mines', in A Karzulovic \& MA Alfaro (eds), Proceedings of MassMin 2004, Instituto de Ingenieros de Chile, Santiago, pp. 135-140.

Khodayari, F \& Pourrahimian, Y 2014, 'Determination of the best height of draw in block cave sequence optimization', in R Castro (ed.), Proceedings of the 3rd International Symposium on Block and Sublevel Caving, Universidad de Chile, Santiago, pp. 457-465.

Khodayari, F \& Pourrahimian, Y 2015a, 'Determination of development precedence for drawpoints in block-cave mining', in MP Nicolai (ed.), Proceedings of the 5th International Symposium: Mineral Resources and Mine Development, RWTH Aachen University, Aachen, pp. 383-391.

Khodayari, F \& Pourrahimian, Y 2015b, 'Mathematical programming applications in block-caving scheduling: a review of models and algorithms', International Journal of Mining and Mineral Engineering, vol. 6, no. 3, pp. 234-257.

Khodayari, F \& Pourrahimian, Y 2017, 'Production scheduling in block caving with consideration of material flow', Aspects in Mining and Mineral Science, vol. 1, no. 1.

Laubscher, DA 2000, A Practical Manual on Block Caving, prepared for International Caving Study, Julius Kruttschnitt Mineral Research Centre, Indooroopilly, and Itasca Consulting Group, Inc., Brisbane.

Pourrahimian, Y, Askari-Nasab, H \& Tannant, D 2013, 'A multi-step approach for block-cave production scheduling optimization', International Journal of Mining Science and Technology, vol. 23, no. 5, pp. 739-750.

Rahal, D, Dudley, J \& Hout, Gv 2008, 'Developing an optimised production forecast at Northparkes E48 mine using MILP', in H Schunnesson \& E Nordlund (eds), Proceeding of MassMin 2008, Luleå University of Technology, Luleå, pp. 227-236.

Rubio, E 2002, Long Term Planning of Block Caving Operations Using Mathematical Programming Tools, MSc thesis, The University of British Columbia, $126 \mathrm{p}$. 
